\title{
PBX 9501 Outgas Analysis by SPME/GC/MS
}

D.M. Chambers

\section{December 11, 2000}

U.S. Department of Energy

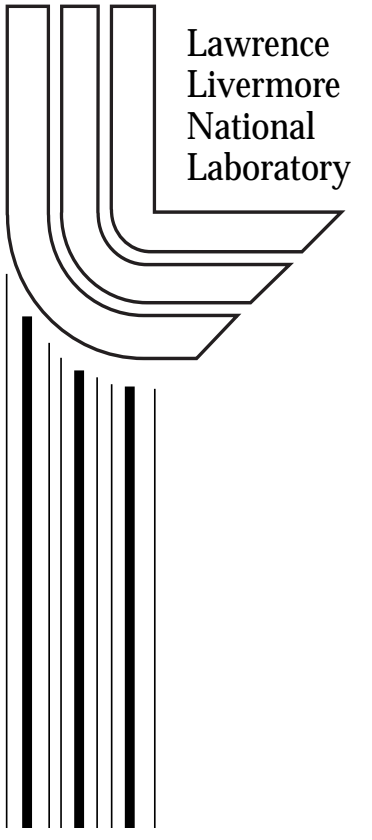




\section{DISCLAIMER}

This document was prepared as an account of work sponsored by an agency of the United States Government. Neither the United States Government nor the University of California nor any of their employees, makes any warranty, express or implied, or assumes any legal liability or responsibility for the accuracy, completeness, or usefulness of any information, apparatus, product, or process disclosed, or represents that its use would not infringe privately owned rights. Reference herein to any specific commercial product, process, or service by trade name, trademark, manufacturer, or otherwise, does not necessarily constitute or imply its endorsement, recommendation, or favoring by the United States Government or the University of California. The views and opinions of authors expressed herein do not necessarily state or reflect those of the United States Government or the University of California, and shall not be used for advertising or product endorsement purposes.

This work was performed under the auspices of the U. S. Department of Energy by the University of California, Lawrence Livermore National Laboratory under Contract No. W-7405-Eng-48.

This report has been reproduced directly from the best available copy.

Available to DOE and DOE contractors from the

Office of Scientific and Technical Information

P.O. Box 62, Oak Ridge, TN 37831

Prices available from (423) 576-8401

http://apollo.osti.gov/bridge/

Available to the public from the National Technical Information Service

U.S. Department of Commerce 5285 Port Royal Rd., Springfield, VA 22161

http://www.ntis.gov/

OR

Lawrence Livermore National Laboratory Technical Information Department's Digital Library http://www.llnl.gov/tid/Library.html 


\title{
Lawrence Livermore National Laboratory
}

\section{PBX 9501 Outgas Analysis by SPME/GC/MS Files $R$ W002829-53, RW003205}

Version Date: December 11, 2000

Prepared by:

David M. Chambers, Ph.D.

chambers10@llnl.gov

Weapon Materials Compatibility \& Aging Program Element

Lawrence Livermore National Laboratory, Livermore CA 94551

P.O. Box 808, L-178

Livermore, CA 94551

Phone (925) 422-5607

FAX: (925) 423-9014

\begin{abstract}
We used equilibrium headspace gas chromatography/mass spectrometry (GC/MS) to monitor volatile and semivolate species that are expected to migrate through PBX 9501 under environmentally relevant conditions. In this work we screened 11 samples taken from deployed parts. Although a number of chemical permeates were identified, the antioxidant signature provided the most information with regard to decomposition aging. Specifically, we were able to monitor butylated hydroxytoluene (BHT) and other antioxidants, which are apparently added to either the Estane adipate or MDI precursor by the manufacturer. We found that in those parts where diphenylamine (DPA) was used as a stabilizer, BHT response was significantly lower than in those formulations stabilized with Irganox 1010 (Irganox).
\end{abstract}

These results imply that DPA is less efficient as a radical scavenger than Irganox. This lower efficiency might be related to the lack of oxygen in the weapon environment, which is initially $<0.1 \%$. With regard to DPA, it has been reported that radical scavenging activity is proportional to the oxygen pressure. At this time we are uncertain whether the low DPA efficiency is mainly attributed to the oxygen level or if there is another rate limiting step that would lead to the preferential consumption of BHT.

It should also be noted that because BHT and DPA are semivolatile compounds, these species can be depleted if the PBX 9501 is stored for long periods of time at elevated temperatures. This can be the case for molding powder stored in outdoor bunkers. In the addendum, we report significantly depleted volatile and semivolatile compound signature for Lot 730-010 molding powder stored in outdoor bunkers at Pantex. This particular lot was formulated with Irganox as the stabilizer, which is essentially a nonvolatile compound. Although analysis of this material will yield decreased BHT levels with time, resulting mainly from the storage and handling conditions of the molding powder, we would expect free radical activity to be controlled by the Irganox.

In addition to the outward diffusion of ingredients, we identified a significant polysiloxane degradation signature that apparently diffuses in from the weapon environment. From recent work at LLNL, we are able to distinguish irradiation-, heat- and chemical incompatibility-induced decomposition byproducts. Because a combination of cyclic and linear siloxane products were found, we believe that this signature signifies chemical incompatibility-initiated decomposition of the weapon polysiloxanes. 


\section{BACKGROUND}

The purpose of this work is to complement liquid sample preparation and analysis of the PBX 9501 formulation ingredients. ${ }^{1}$ The approach described here permits detection and identification of species that exist as trapped volatiles as well as of semivolatile compounds that are difficult to collect and analyze without volatilization loss or dilution. For this work, we prepared equilibrium headspace samples from PBX 9501. This procedure involves outgassing the material in a sealed headspace vial and either dynamically or statically collecting the gas-phase chemicals for analysis. Here, we used the static headspace collection approach involving solid phase microextraction (SPME) collection followed by gas chromatography/mass spectrometry (GC/MS) analysis.

The PBX 9501 samples were taken from the radial core specimens of specific weapon components. PBX 9501 is composed nominally of $94.9 \mathrm{wt} \%$ 1,3,5,7-tetranitro-1,3,5,7tetrazacyclooctane (HMX), $2.5 \mathrm{wt} \%$ Estane $5703 \mathrm{~F}-1,2.5 \mathrm{wt} \%$ nitroplasticizer, and 0.1 wt $\%$ stabilizer. Before 1980 the antioxidant stabilizer used was diphenylamine (DPA). After 1980, it was switched to Irganox 1010 (Irganox). Parts and their pedigrees are listed in Table I.

For the materials we analyzed, only the antioxidant signature provided any evidence of material degradation. Often, the state of the antioxidants (or stabilizers) provides the first indication of material degradation. Antioxidants are used to neutralize free radicals, which can be produced by different processes including material incompatibility, heating, irradiation, and mechanical damage. These free radicals react quickly with $\mathrm{O}_{2}$ at a rate on the order of $10^{9} \mathrm{M}^{-1} \mathrm{sec}^{-1}$ to form peroxide radicals. It is these peroxide radicals that typically react with antioxidants. The reaction of $\mathrm{O}_{2}$ directly with most organic substrates is thermodynamically and kinetically unfavorable at low-to-moderate temperatures and is not expected to be as significant as free radical degradation. Therefore, "oxidation" degradation of most materials is likely initiated by radical formation. In this work, we evaluate "oxidation" degradation by monitoring antioxidant levels, antioxidant byproducts and polymer degradation byproducts.

Other aging processes that we typically monitor include the outgassing of species from a material and the absorption of compounds from the weapon environment. For these measurements to be meaningful, we must be able to control the material once it is removed from its aging environment. Unfortunately, this is not easily accomplished if the material has to be machined and handled over a relatively long period of time. In this case, many of the synthesis and formulation volatiles can be lost while outside contaminants are absorbed. For this reason, we focus our analysis on semivolatile species that are not easily lost or absorbed during subsequent handling.

\footnotetext{
${ }^{1}$ Campbell, M.S.; King, W.F. "PBX 9501 Library Lot Sample Analyses: High Explosives Enhanced Surveillance Project”; LA-13650-MS; Los Alamos National Laboratory: Los Alamos, NM, November 1999.
} 
Table I. PBX 9501 sample pedigree

\begin{tabular}{c|c|c|c|c|c|c|c}
$\begin{array}{c}\text { Age } \\
(\mathrm{mo})\end{array}$ & Cycle No. & RB No. & $\begin{array}{c}\text { Hemi No. } \\
\text { (Fwd) }\end{array}$ & $\begin{array}{c}\text { Hemi No. } \\
\text { (Aft) }\end{array}$ & $\begin{array}{c}\text { PBX 9501 } \\
\text { Lot No. }\end{array}$ & $\begin{array}{c}\text { PBX 9501 Lot } \\
\text { Manufacture Date }\end{array}$ & Estane Lot No. \\
\hline 238 & No Cy & 788654 & 1020348 & & $685-001$ & $9 / 22 / 77$ & 658316 \\
\hline 209 & No Cy & 423816 & 1030508 & & $685-002$ & $9 / 27 / 77$ & 658316 \\
\hline 217 & No Cy & 606936 & 1040815 & & $685-004$ & $9 / 27 / 77$ & 660231 \\
\hline 190 & 17 & 772469 & & 2051306 & $685-005$ & $12 / 15 / 78$ & 660213 \\
\hline 213 & No Cy & 600632 & 1051349 & & $685-005$ & $12 / 15 / 78$ & 660231 \\
\hline 100 & 19 & 228739 & 1061907 & & $685-006$ & $8 / 9 / 79$ & 660543 \\
\hline 154 & 18 & 817485 & 1080904 & & $730-004$ & $10 / 2 / 80$ & 663760 \\
\hline 148 & 20 & 919078 & 1100214 & & $730-006$ & $5 / 4 / 83$ & 666865 \\
\hline 108 & 17 & 250798 & 1100110 & & $730-006$ & $5 / 4 / 83$ & 666865 \\
\hline 209 & No Cy & 423816 & & 2030542 & $685-002$ & $9 / 27 / 79$ & 658316 \\
\hline 230 & No Cy & 361540 & 1030916 & & $685-002$ & $9 / 27 / 79$ & 658316
\end{tabular}

\section{EXPERIMENTAL}

The PBX 9501 samples were analyzed using SPME collection followed by GC/MS analysis. This approach was selected because of its high collection and preconcentration efficiency. In particular, this method focuses on the volatile to semivolatile compounds that are otherwise difficult to collect by liquid extraction because of dilution and interference by a solvent.

For these analyses, we shaved a 500-mg sample from the end of each radial core from reference position $15 .^{3}$ Nine of the eleven core samples were taken from a forward hemi and two from an aft. Each sample was sealed in a standard 20-ml headspace vial using a Teflon barrier, butyl rubber septa cap. We did not use the more common silicone seals so as to avoid contamination of the samples with siloxanes, which are often of interest. We believe that the siloxane signature outgassed from PBX 9501 is contamination that was absorbed from other weapon materials. Following sample preparation, we heated the vials to $50^{\circ} \mathrm{C}$ for approximately 5 days to accelerate outgassing of the trapped species. The samples were then transported to a laboratory where they were extracted by SPME at $24^{\circ} \mathrm{C}$ for $60 \mathrm{~min}$.

Analyses were performed on a Hewlett-Packard 5890/5972 GC/MS with a 0.75-mm i.d. injection port liner. A $60-\mathrm{m}$ long by $0.25-\mathrm{mm}$ i.d. capillary coated with a $1.4-\mu \mathrm{m}$ thick (6\%-cyanopropyl-phenyl)-methylpolysiloxane bonded-phase (J\&W Scientific, DB-624) was used for the GC separation. This column, which permits the analysis of volatile

\footnotetext{
${ }^{2}$ Lightfoot, M.J. "PBX 9501 Composition in Production Lots and Surveillance Samples"; DOE/AL/650309901; Pantex Plant: Amarillo, TX, February 1999.

${ }^{3}$ Overturf, G.E.; Lewis, P.R. "PBX 9501 Molecular Weight Analyses of W76 DREV Project Samples"; Lawrence Livermore National Laboratory: Livermore, CA, submitted.
} 
compounds at relatively high GC oven temperatures, was primarily used to take advantage of the existing retention-time database that we maintain for this column phase.

Ideally, we would have preferred to take several samples from a single core to evaluate variation in response throughout a radial core, however, this opportunity was not possible. Nevertheless, we are able to estimate method variance by comparing the response for a compound that is likely a process contaminant. One of the most common is hexamethyl cyclotrisiloxane, which is a relatively volatile siloxane that will equilibrate with the manufacturing environment. Shown in Fig. 1 is a comparison of hexamethyl cyclotrisiloxane response from the 11 cores samples. If each sample is able to equilibrate with the surrounding environment, then the relative standard deviation (RSD $=\mathrm{SD} / \mathrm{mean}$ ) of $15 \%$ is indicative of the precision of the combined handling and analysis process. It is important to note that this cyclic siloxane is also a common decomposition product of certain weapon polysiloxanes, however, we believe that the weapon signature is lost in handling as it is a relatively volatile compound.

Figure 1

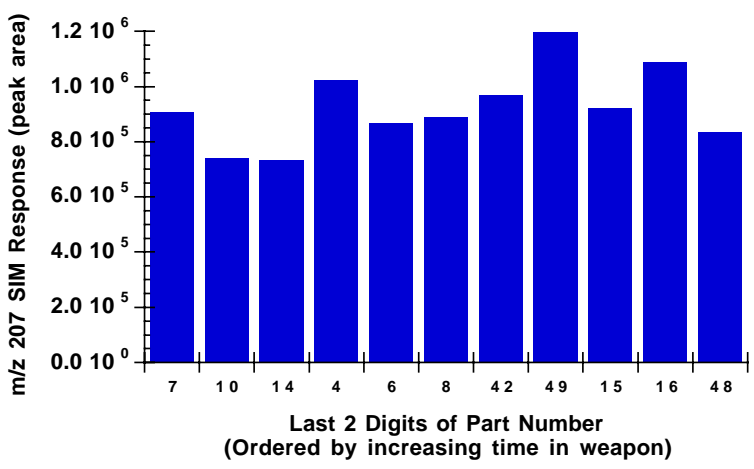

Figure 1. PBX 9501 outgas response for hexamethyl cyclotrisiloxane, a common volatile industrial contaminant. Low \% RSD compared to other outgas signatures suggests that this compound exists as a process contaminant. In this case, relative response is indicative of the method precision.

\section{RESULTS}

We found 31 significant compounds. The list of these compounds and their single ion monitoring (SIM) responses for a significant ion are given in Table II. The significant ion was selected on the basis of its relative response and interference from background or coeluting compounds. Structures for these compounds can be found using the CAS number at http://www.chemfinder.camsoft.com/. Each of these species can be traced back to specific materials. These species are (1) byproducts left in the materials following synthesis and formulation, (2) degradation products, and (3) contaminants. For the PBX 9501 we were able to detect a number of Estane byproducts and the DPA stabilizer. We were not able to collect the nitroplasticizers or Irganox because of the low collection temperature at which the material had to be handled. 
Table II. Outgas signature list for PBX 9501

\begin{tabular}{|c|c|c|c|c|c|c|c|c|c|c|c|c|c|c|c|}
\hline & \multicolumn{14}{|c|}{ Run Number RW0028* } \\
\hline & & $* 29$ & $* 31$ & $* 33$ & $* 35$ & $* 37$ & *39 & *41 & $* 43$ & $* 49$ & $* 52$ & $* 53$ & & & \\
\hline Compound & $\begin{array}{c}\text { CAS } \\
\text { Number }\end{array}$ & $\begin{array}{r}761080904 \\
-15 \text { Mid Dot } \\
\end{array}$ & \begin{tabular}{|c|}
762051306 \\
-15 RC Dot \\
\end{tabular} & $\begin{array}{r}761061907 \\
-15 \text { RC Dot } \\
\end{array}$ & \begin{tabular}{|l|}
761030508 \\
-15 RC Dot \\
\end{tabular} & \begin{tabular}{|l|}
761100110 \\
-15 RC Dot
\end{tabular} & \begin{tabular}{|l|}
761040815 \\
-15 Mid Dot
\end{tabular} & \begin{tabular}{|l|}
$761030916 \backslash$ \\
-15 RC Dot \\
\end{tabular} & \begin{tabular}{|l|}
761100214 \\
-15 RC Dot
\end{tabular} & \begin{tabular}{|l|}
762030542 \\
-15 RC Dot \\
\end{tabular} & \begin{tabular}{|l|}
761051349 \\
-15 Mid Dot \\
\end{tabular} & \begin{tabular}{|l|}
761020348 \\
-15 Mid Dot \\
\end{tabular} & $\begin{array}{l}\text { R.T. } \\
(\mathrm{min})\end{array}$ & $\begin{array}{l}\text { Sig. } \\
\text { Ion }\end{array}$ & $\begin{array}{c}\text { MW } \\
\text { (amu) }\end{array}$ \\
\hline 2-butanone & $78-93-3$ & $6,898,292$ & $6,435,006$ & $9,012,389$ & $7,200,071$ & $5,133,077$ & $3,980,807$ & $6,774,463$ & $4,885,293$ & $8,289,978$ & $9,292,615$ & $8,757,769$ & 11.408 & 72 & 72 \\
\hline benzene & $71-43-2$ & 303,897 & 256,440 & 323,006 & 317,208 & 343,006 & 421,900 & 461,334 & 469,374 & 301,098 & 523,776 & 677,258 & 12.665 & 78 & 78 \\
\hline glycol & 000-00-0 & 191,457 & 134,627 & 148,322 & 122,189 & 127,301 & 137,854 & 135,451 & 150,064 & 158,889 & 153,196 & 185,416 & 13.990 & 88 & \\
\hline hexamethylcyclo trisiloxane & $541-05-9$ & 960,684 & $1,570,370$ & $1,461,753$ & 929,954 & $1,503,736$ & $1,535,352$ & $1,558,447$ & $1,833,205$ & $1,541,428$ & $1,476,463$ & $1,665,762$ & 15.930 & 207 & 222 \\
\hline polysiloxane & $000-00-0$ & 284,662 & 99,276 & 235,944 & 39,338 & 68,099 & 61,773 & 56,005 & 148,539 & 85,539 & 199,311 & 159,846 & 16.470 & 149 & 154 \\
\hline octamethyl trisiloxane & $107-51-7$ & 123,689 & 37,875 & 101,988 & 23,987 & 57,801 & 8,736 & 27,558 & 140,449 & 52,874 & 51,151 & 53,374 & 17.310 & 221 & 236 \\
\hline ethylbenzene & $100-41-4$ & 210,180 & 32,024 & 152,728 & 64,233 & 53,981 & 119,013 & 41,404 & 144,665 & 53,529 & 57,311 & 125,229 & 18.120 & 91 & 106 \\
\hline m,p-xylene & $95-47-6$ & 627,556 & 96,170 & 436,594 & 171,115 & 183,500 & 382,648 & 95,989 & 428,367 & 129,276 & 142,476 & 341,124 & 18.310 & 91 & 106 \\
\hline 4-hydroxy-4-methyl- 2-pentanone & $123-42-2$ & 217,913 & 186,073 & 183,231 & 146,032 & 124,821 & 132,994 & 98,632 & 141,391 & 157,437 & 200,415 & 243,879 & 18.590 & 101 & 116 \\
\hline o-xylene & $108-38-3$ & 487,260 & 75,203 & 326,259 & 183,376 & 101,275 & 464,418 & 111,698 & 316,160 & 110,818 & 115,854 & 338,008 & 19.040 & 91 & 106 \\
\hline decamethyl tetrasiloxane & $141-62-8$ & 428,845 & 30,406 & 143,915 & 21,974 & 40,978 & 50,847 & 35,542 & 329,564 & 47,338 & 109,317 & 100,417 & 21.530 & 207 & 295 \\
\hline 2-ethylhexanol & 104-76-7 & 198,958 & 135,564 & 200,255 & 54,399 & 153,672 & 177,725 & 224,371 & 70,395 & 190,155 & 269,185 & 273,012 & 22.310 & 83 & 130 \\
\hline phenol & $108-95-6$ & 558,484 & 244,269 & 638,881 & 556,058 & 218,317 & 576,143 & $1,121,051$ & 381,840 & $1,028,036$ & 696,809 & $1,789,465$ & 22.752 & 94 & 94 \\
\hline decamethyl cyclo pentasiloxane & $541-02-6$ & $1,595,216$ & 692,051 & $4,298,795$ & $3,682,122$ & 431,109 & $4,953,561$ & $1,924,592$ & $1,359,466$ & $1,501,355$ & $2,998,338$ & $1,709,126$ & 23.430 & 267 & 370 \\
\hline nonanal & $124-19-6$ & 31,309 & 24,385 & 27,749 & 24,171 & 28,384 & 24,687 & 17,168 & 37,261 & 19,202 & 32,483 & 28,013 & 23.887 & 98 & 142 \\
\hline dodecamethyl pentasiloxane & 141-63-9 & $1,410,516$ & 553,676 & $3,662,314$ & $1,808,281$ & 316,626 & $7,298,782$ & $4,907,133$ & $1,322,911$ & 712,636 & $2,250,984$ & $1,874,656$ & 23.982 & 281 & 384 \\
\hline unknown & 000-00-0 & 46,938 & 31,411 & 39,789 & 26,613 & N.D. & 46,938 & 19,940 & 13,173 & 23,105 & 77,964 & 33,905 & 24.870 & 100 & \\
\hline dodecamethyl cyclo hexasiloxane & $540-97-6$ & 294,834 & 89,436 & 727,680 & 774,661 & 57,353 & $2,128,767$ & 427,705 & 217,856 & 215,595 & 806,753 & 385,184 & 26.802 & 341 & 444 \\
\hline polyaromatic Unknown & $000-00-0$ & 29,655 & 15,841 & 25,209 & 19,530 & 34,867 & 21,334 & 24,005 & 10,184 & 15,584 & 41,959 & 22,186 & 28.510 & 160 & \\
\hline polyaromatic Unknown & $000-00-0$ & 31,430 & 25,971 & 30,145 & 19,787 & 38,837 & 30,369 & 30,255 & 11,457 & 18,474 & 50,618 & 20,087 & 28.760 & 160 & \\
\hline 2,6-di-tert-butylquinone (DBQ) & $719-22-2$ & N.D. & 6,802 & 29,868 & 21,617 & 23,273 & 71,382 & 91,735 & 33,920 & 92,513 & 167,555 & 96,730 & 31.280 & 177 & 220 \\
\hline unknown & $000-00-0$ & 20,887 & 33,296 & 27,846 & 60,981 & 22,646 & 65,117 & 42,888 & 10,953 & 47,239 & 114,847 & 19,644 & 31.350 & 165 & 221 \\
\hline butylated hydroxytoluene (BHT) & $128-37-0$ & 775,509 & 34,143 & 32,521 & 59,189 & 886,419 & 67,404 & 36,145 & 352,083 & 69,692 & N.D. & 13,637 & 31.393 & 205 & 220 \\
\hline $\begin{array}{l}\text { 2,6-bis(1,1-dimethylethyl) -4- } \\
\text { ethylphenol }\end{array}$ & $4130-42-1$ & $2,857,474$ & 11,691 & 12,904 & 3,456 & $6,678,231$ & 2,856 & 6,616 & $3,230,268$ & 7,659 & 10,201 & N.D. & 32.193 & 219 & 234 \\
\hline polysiloxane & $38147-00-1$ & 63,022 & 34,372 & 121,283 & 35,405 & 24,057 & 43,506 & 45,372 & 42,307 & 18,545 & 56,706 & 20,492 & 35.660 & 429 & 444 \\
\hline $\begin{array}{l}\text { 2,3-dihydro-1,1,3- trimethyl-3- } \\
\text { phenyl-1H-indene }\end{array}$ & $3910-35-8$ & 178,510 & 207,637 & 311,440 & 284,420 & 214,086 & 270,406 & 276,189 & 329,778 & 249,098 & 472,092 & 282,463 & 36.174 & 221 & 236 \\
\hline
\end{tabular}

R.T = retention time, Sig. Ion = significant ion, $M W=$ molecular weight, N.D. $=$ not detected 
Most of the other compounds detected are permeants outgassed by other materials in the weapon headspace. The majority of these permeants are polysiloxane species. Previous work at LLNL has shown that many of these species are decomposition products rather than byproducts left over from synthesis and formulation. ${ }^{4,5}$

A number of the most volatile compounds (e.g., the first six compounds listed in Table II) are attributed to sample handling contamination despite the fact that many of these compounds are also known decomposition products of certain weapon materials. We believe this to be the case with the results shown in Fig. 1 where the compound response from sample-to-sample remained relatively constant indicating that the samples had equilibrated with the process environment. The relative responses for these compounds yielded RSDs below 30\%.

\section{Estane Byproducts}

Volatile byproducts of recently manufactured Estane 5703, a polyester urethane whose simplified structure is shown;

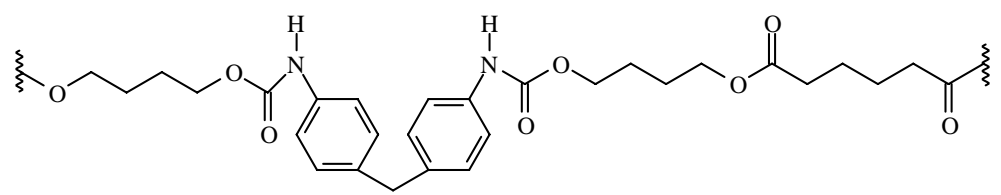

include 1,6-dioxacyclododecane-7,12-dione and butylated hydroxytoluene (BHT) as shown in the analysis of $5703 \mathrm{P}$ (Lot 6EEE3000SKI) in Fig. 2. The 1,6-

dioxacyclododecane-7,12-dione is a cyclized polyester dimer. The BHT is an antioxidant that is apparently incorporated in the MDI precursor. ${ }^{6}$ For the Estane aged under ambient conditions, we see a decrease in the BHT levels and an increase in 2,6-di-tertbutylquinone (DBQ) and 1,4-butanediol. The cyclic polyester fragment only dropped slightly, which suggests that it is a synthesis byproduct that was slowly outgassing. This can be seen in the accompanying spectrum in Fig. 2 of Estane 5703 F (Lot 648313).

\footnotetext{
${ }^{4}$ Chambers, D.M.; King, H.A.; Ithaca, J. I. “Analyzing and Interpreting Outgas Signatures from Nuclear Weapons (U)"; submitted for publication in Defense Nuclear Review.

${ }^{5}$ Chien, A.; Maxwell, R.; Chambers, D.; Balazs, B.; LeMay, J. Radiat. Phys. Chem., in press.

${ }^{6}$ Kim, Kenneth B.F. Goodrich Company, personal communication, 2000.
} 
Figure 2

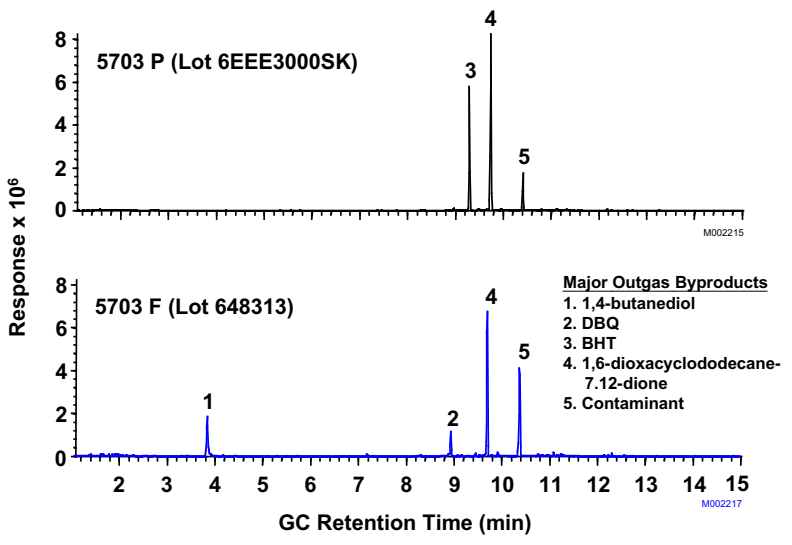

Figure 2. Comparison of volatile byproducts from new (5703 P) and old (5703 F) Estane. With age the BHT is consumed, whereas $D B Q$ and 1,4-butanediol are formed.

In the analysis of the PBX 9501 samples, we did not detect significant levels of 1,4butanediol. This volatile compound was likely lost throughout the lengthy sample handling procedure. Although the cyclic polyester fragment, 1,6-dioxacyclododecane7,12-dione, was detectable, its response was low and appeared to be more dependent on lot than age. This result is in agreement with current belief that this compound is a synthesis byproduct and not a degradation product.

As shown in Fig. 3, a significant loss of BHT is seen in those samples where DPA was used. In those same parts, as shown in Fig. 4, we also detected lower levels of Ionol 2 [2,6-bis(1,1-dimethylethyl)-4-ethylphenol], which is also a hindered phenol antioxidant similar to BHT. DPA was found in all samples except those from parts 761080904-15, 761100110-15 and 761100214-15 as shown in Fig 5.

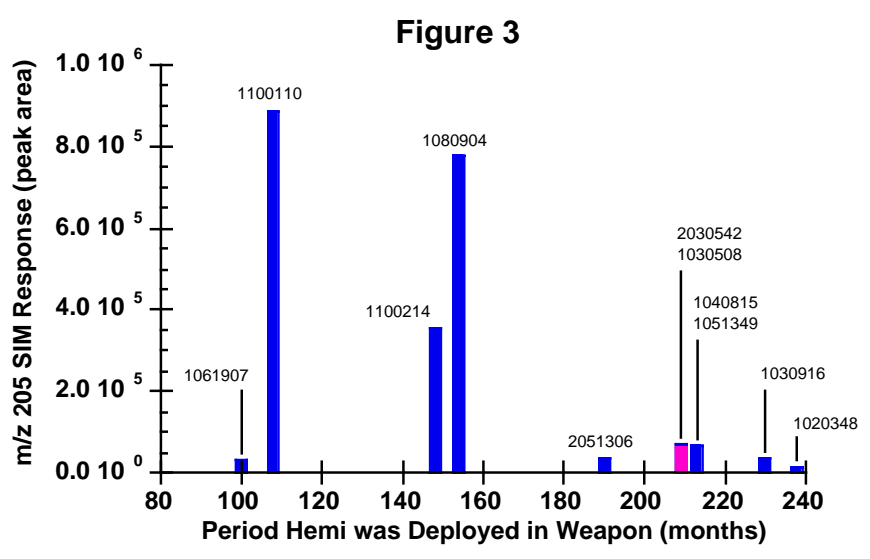

Figure 3. Response for the antioxidant BHT from the PBX 9501 samples. Those parts using DPA as a stabilizer (this includes all parts except 11100110 , 1100214, and 1080904) were significantly depleted in BHT. 


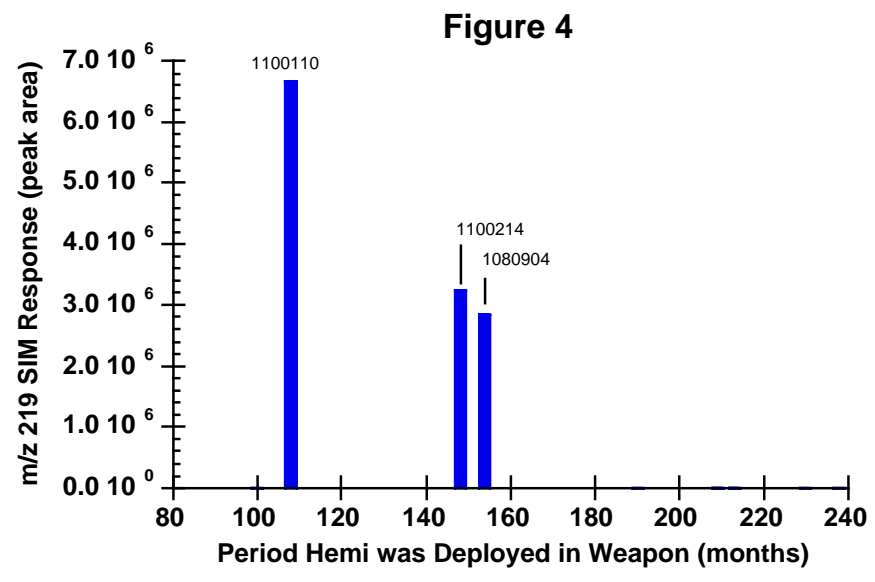

Figure 4. Response for the antioxidant Ionol 2 from the PBX 9501 samples. Those parts using DPA (see all except 1100110, 1100214, and 1080904) as a stabilizer were significantly depleted in Ionol 2. 
Figure 5

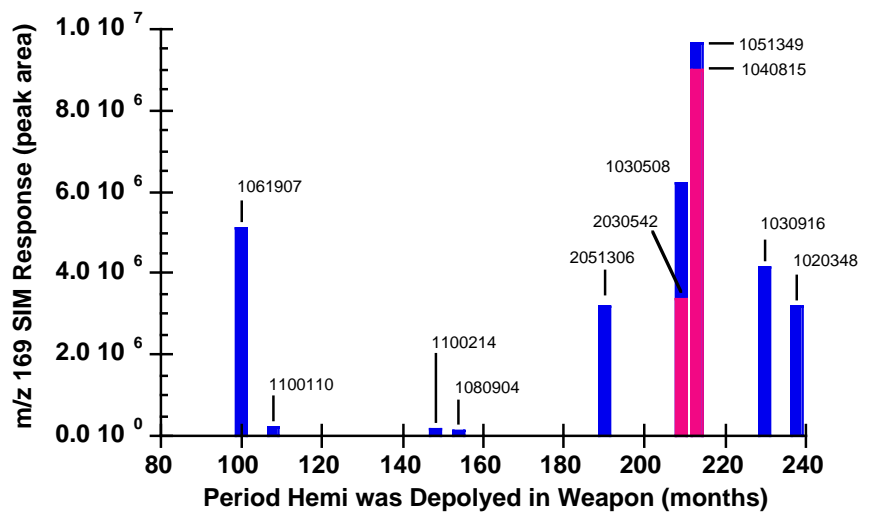

Figure 5. Relative volatile response for the antioxidant $D P A$ from the $P B X 9501$ samples

We believe that the consumption of BHT and Ionol 2 and the formation of DBQ suggests a detectable level of free radial activity in the Estane. Basically, antioxidants are radical scavengers. Once the radical is formed, it reacts very quickly with $\mathrm{O}_{2}$ to form a peroxide. The antioxidants, which include DPA, Irganox, BHT and Ionol 2, readily react with peroxide radicals.

At this time, we are uncertain as to the source of the DBQ byproduct. Typically, DBQ is formed by reaction of 2,6-di-tert-butyl-phenol with a radical peroxide as shown below

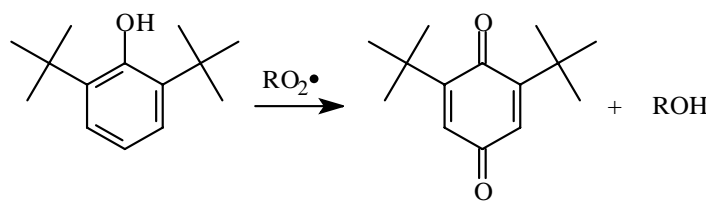

However, we did not detect the 2,6-di-tert-butyl-phenol precursor and, therefore, believe that the DBQ is a byproduct of BHT consumption. We also see DBQ in bulk Irganox.

It is our understanding in the case of DPA that a stable nitroxide radical is formed in a reaction between its amino radical precursor and a peroxy radical. After the nitroxide radical is formed, it can react directly with an alkyl radical ${ }^{7}$. The sequence of these reactions is given below
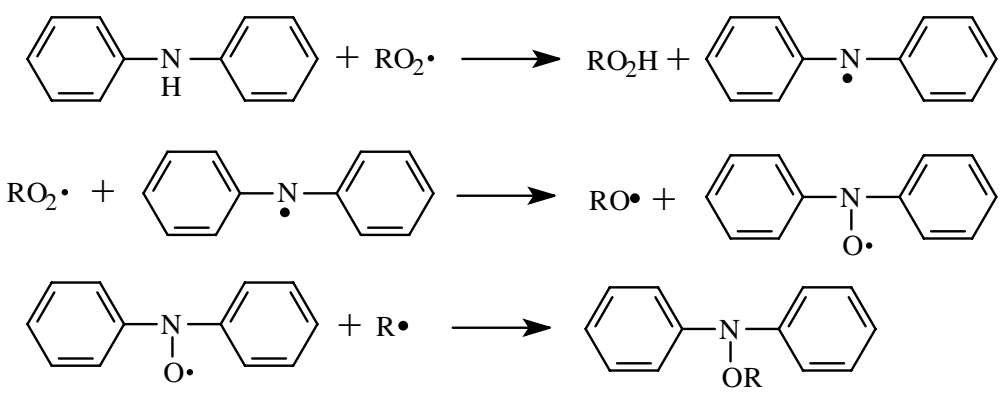

\footnotetext{
${ }^{7}$ Kamiya, Y.; Niki, E. Aspects of Degradation and Stabilization of Polymers; Jellinek, H.H.G., Ed.: Elsevier Scientific, New York, 1978, p 103.
} 
For DPA to act as a radical scavenger, which is one of its primary uses, it must first react with a peroxide radical. Because the weapon environment is oxygen poor, the formation of the peroxide and the DPA nitroxide that follows at slower rate, will lower DPA's efficiency as a radical scavenger. Inhibited rates of oxidation are proportional to the oxygen pressure, inversely proportional to the nitroxide concentration and independent of the substrate concentration as shown below

$$
\mathrm{R}_{\text {inh }} \propto \frac{\mathrm{P}_{\mathrm{O}_{2}}}{\text { nitroxide }}
$$

As deduced from recent gas analyses, oxygen content in the weapon headspace is initially $<0.2 \%$, which apparently decreases over the years for non leaking units. ${ }^{8}$ If these low $\mathrm{O}_{2}$ conditions inhibit activation of the DPA, then this might explain why the BHT and Ionol 2 were depleted in the formulations that used DPA. That is, in the absence or deficiency of $\mathrm{O}_{2}$, we would expect the efficiency of the hindered phenol antioxidants (e.g., Irganox) to be greater than the amine-based antioxidants (e.g., DPA). As the lifetime of the radical is increased, the depolymerization and chain transfer reactions will be promoted. If this is the case, then stiffness, creep resistance and brittleness will be expected to vary.

\section{Siloxane Signature}

From these analyses, it became apparent that there is a significant siloxane signature that is indicative of degradation. Those parts from which we found the highest levels of absorbed siloxanes include 761040815-15, 761061907-15 and 761030508-15, $761051349-15$, listed in decreasing order of response. Shown in Fig. 6 is a comparison of the siloxane signature for the semivolatile cyclic siloxanes. Each sample is designated by the last two digits of the part number from which it came and the results are ordered by increasing months spent in the weapon. We believe these species were absorbed from the weapon atmosphere and are not contaminants because they (1) exist at relatively high levels, (2) are not seen in our process blank and (3) are determined to be common degradation byproducts of aged polysiloxanes (see below).

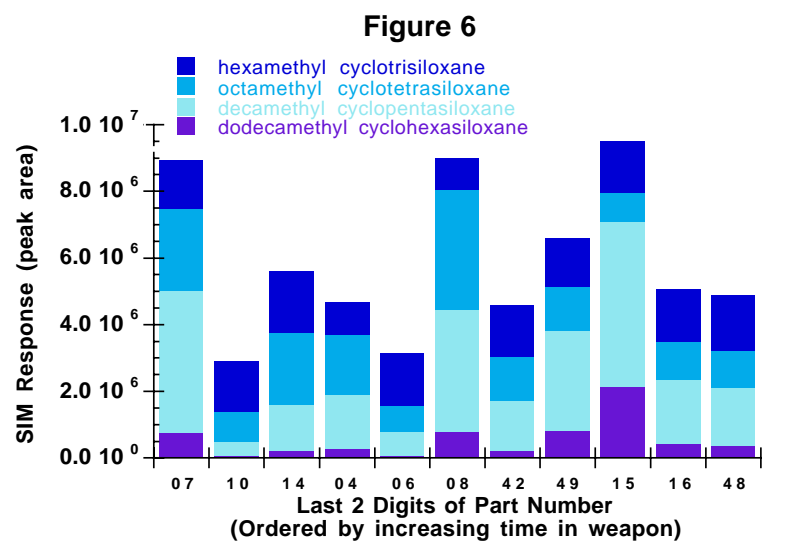

\footnotetext{
${ }^{8}$ Gillen, K.T. "Analysis of W76 Surveillance Gas Results Using the Pacer Approach"; Sandia National Laboratories, Albuquerque: NM, SAND96-1890, July 1996.
}

Figure 6. Cyclic siloxane species absorbed by $P B X$ 9501 samples from the weapon environment. Samples were taken from parts listed in Table I and are identified by the last two digits of the part number. The samples are in order of increasing time spent in weapon. 
Our aging studies of polysiloxanes have shown that this signature is indicative of backbiting decomposition of polydimethylsiloxane segments, which is given below

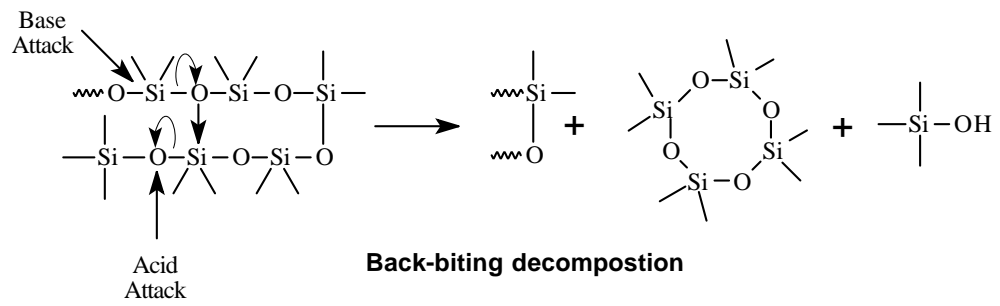

This back-biting reaction can be initiated by chain scission or can occur if the polysiloxane is not end blocked. Although it has been argued that cyclic siloxanes can also be left over from their synthesis, we have found that for LLNL materials, these species exist at only trace levels and are readily lost during formulation and post processing. We expect the same for the LANL materials. Linear siloxanes are not generally found in new materials but can be produced from a combination of chain scission and condensation of silanol groups.

Moreover, other work at LLNL involving the study of polysiloxanes upon heating and exposure to radiation has been shown to produce significant levels of benzene and lower levels of toluene and xylene. ${ }^{5}$ These aromatics are cleaved from any diphenylsiloxane segments of the polymer. In addition, relatively high levels of cyclic siloxanes can be produced. Shown in Fig. 7 is a comparison of M9760 polysiloxane aged for two weeks at 50 and $200^{\circ} \mathrm{C}$. From this study, it is clear that as the material is degraded, cyclic siloxanes are formed.

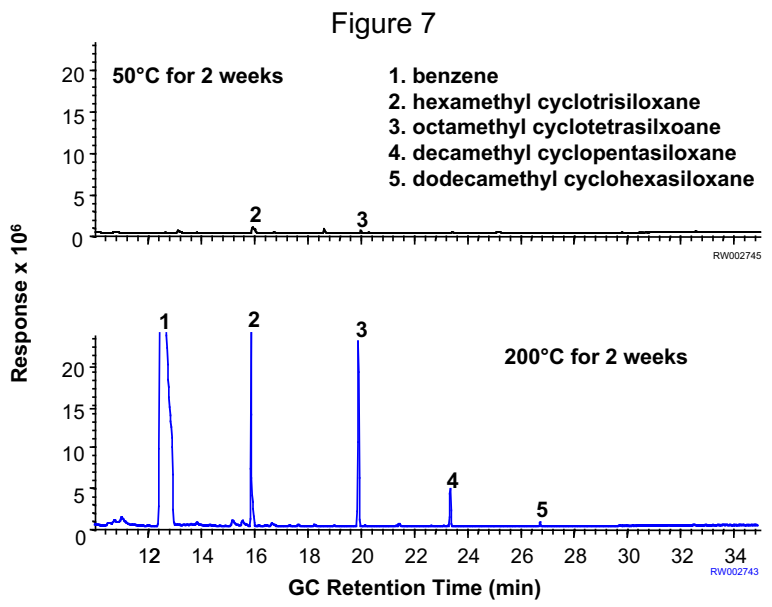

Figure 7. Comparison of outgas response from a M9760 polysiloxane cushion heated under vacuum. Polydimethyl cyclic siloxanes result from back-biting decomposition of polydimethyl segments. The benzene results from cleavage of phenyl side groups of the siloxane copolymer chain.

\section{Conclusions}

Volatile analyses of PBX 9501 from deployed parts revealed two major aging signatures. The first was the adsorption of siloxane degradation byproducts from polysiloxane materials that share the same weapon environment. Those parts that outgas the highest levels of absorbed cyclic siloxanes included Parts 761040815, 761061907, 761030508, 761051349 , listed in decreasing order of response. This response appears to correlate with those samples with the highest DPA levels. At this time, there is not enough 
information to determine whether these elevated cyclic siloxane levels might somehow result from lower depletion loss when the parts are machined, or whether they are directly related to enhanced aging processes. Direct analysis of the different units would verify whether the polysiloxane signature varied independently from the DPA response.

The volatile signature from the PBX 9501 that we monitored were primarily derived from Estane and the DPA stabilizer. The only aging signatures we could detect, given the sample history, include BHT, Ionol 2, DBQ and DPA, which are antioxidants and antioxidant byproducts. We found that these species can be monitored to track initial stages of decomposition. In those formulations that used DPA, we detected only trace levels of BHT and Ionol 2, which are hindered phenol antioxidants included in the Estane formulation. In addition, levels of DBQ, a byproduct of antioxidant decomposition, were elevated.

Altogether these results suggest that the DPA antioxidant efficiency is compromised, resulting in preferential consumption of the hindered phenol antioxidants-BHT and Ionol 2. In this case, one would expect the PBX 9501 formulated with DPA (Lot 685$\mathrm{xxx}$ ) to experience a higher level of free radical activity than in the PBX 9501 using Irganox 1010 (Lot 730-xxx). 


\section{ADDENDUM}

Following this study, we were asked to analyze the PBX 9501 Lot 730-010 molding powder described in Table III. Unlike the weapon material samples, this molding powder was stored at Pantex in an outdoor bunker with no special environmental controls to regulate temperature and humidity since its manufacture. The upper heat load for a storage bunker is approximately $32^{\circ} \mathrm{C}$. Given these conditions the volatile and semivolatile species are expected to diffuse from the material. This is different from the pressed part samples, where migrating species must diffuse through the bulk part to escape.

Table III. PBX 9501Lot 730-010 pedigree

\begin{tabular}{|c|c|c|c|c|c|c|c|}
\hline $\begin{array}{c}\text { Age } \\
(\mathrm{mo})\end{array}$ & Cycle No. & RB No. & $\begin{array}{c}\text { Hemi No. } \\
\text { (Fwd) }\end{array}$ & $\begin{array}{c}\text { Hemi No. } \\
\text { (Aft) }\end{array}$ & $\begin{array}{c}\text { PBX 9501 } \\
\text { Lot No. }\end{array}$ & $\begin{array}{c}\text { PBX 9501 Lot } \\
\text { Manufacture Date }^{2}\end{array}$ & Estane Lot No. \\
\hline 0 & No Cy & NA & NA & & $730-010$ & $4 / 10 / 89$ & 6040200 \\
\hline
\end{tabular}

From the identification list given in Table IV, we detected a number of cyclic siloxane compounds at the trace level. Although these compounds have been shown to be thermal decomposition products of certain weapon materials, they are also common environmental contaminants than can be readily absorbed.

Table IV. Outgas signature list for PBX 9501.

\begin{tabular}{|c|c|c|c|c|c|}
\hline \multicolumn{2}{|l|}{ 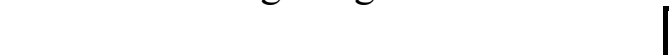 } & \multicolumn{4}{|c|}{ Run Number RW003205 } \\
\hline Compound & $\begin{array}{c}\text { CAS } \\
\text { Number }\end{array}$ & $\begin{array}{c}\text { Lot 730-010 } \\
\text { Molding Powder }\end{array}$ & $\begin{array}{l}\text { R.T. } \\
\text { (min) }\end{array}$ & Sig. Ion & $\begin{array}{c}\text { MW } \\
\text { (amu) }\end{array}$ \\
\hline 2-butanone & $78-93-3$ & 158,709 & 11.408 & 72 & 72 \\
\hline toluene & $108-88-3$ & $4,129,968$ & 15.50 & 91 & 92 \\
\hline hexamethylcyclo trisiloxane & $541-05-9$ & 50,212 & 15.930 & 207 & 222 \\
\hline octamethyl cyclotetrasiloxane & $556-67-2$ & 6,275 & 19.963 & 281 & 296 \\
\hline dodecamethyl cyclo hexasiloxane & $540-97-6$ & 1,189 & 26.802 & 341 & 444 \\
\hline butylated hydroxytoluene (BHT) & $128-37-0$ & 17,042 & 31.393 & 205 & 220 \\
\hline 1,6-dioxacyclododecane-7,12-dione & $777-95-7$ & 1,177 & 33.621 & 129 & 200 \\
\hline
\end{tabular}

R.T $=$ retention time, Sig. Ion $=$ significant ion, $\mathrm{MW}=$ molecular weight

Although the outgas response for this PBX 9501 Lot 730-010 is low, the relative levels of BHT were comparable to the other samples (i.e., 761080904, 761100110, and 761100214) stabilized with Irganox instead of DPA. This similarity is determined by comparing the ratio of BHT to 1,6-dioxacyclododecane-7,12-dione, which is on the order of 10 to 30 for those lots formulated with Irganox. As discussed in the initial report, BHT can be monitored to assess antioxidant activity. Conversely, we believe that 1,6dioxacyclododecane 7,12-dione is an Estane synthesis byproduct. If both these species are expected to diffuse out at approximately the same rate then their ratio is comparable with the other Irganox containing lots. 


\section{Conclusions}

PBX 9501 Lot 730-010 molding powder was depleted of volatile and semivolate constituents, which is not surprising given its high surface area form and storage at temperatures of up to $32^{\circ} \mathrm{C}$. Because Irganox is essentially a nonvolatile stabilizer, it is expected not to diffused from the material during storage. In other PBX 9501 lots that use DPA as the stabilizer, we would expect the DPA to diffuse out of the material leaving the material open to radical-attack initiated decomposition, which may be identified by monitoring BHT levels. In Lot 730-010 we see that relative levels of BHT remain consistent with those of the other Irganox stabilized samples (i.e., from parts 761080904 , 761100110, and 761100214). 